\title{
Acceptability and proximate composition of two Filipino delicacies, puto seko and panganan from arrowroot (Maranta arundinaceae, L.) starch
}

\author{
${ }^{1 *}$ Blase, M.E.M. and ${ }^{2}$ Labay P.M. \\ ${ }^{I}$ School of Agriculture, Fisheries, and Natural Sciences, Marinduque State College, Poctoy, Torrijos, \\ Marinduque, Philippines 4903 \\ ${ }^{2}$ School of Technology, Marinduque State College, Tanza, Boac, Marinduque, Philippines 4900
}

\author{
Article history: \\ Received: 2 June 2017 \\ Received in revised form: 7 \\ July 2017 \\ Accepted: 8 July 2017 \\ Available Online: 14 July \\ 2017
}

\section{Keywords:}

Arrowroot,

Arrowroot starch,

Filipino delicacies,

Maranta arundinacea,

Panganan,

Puto seko

DOI:

http://doi.org/10.26656/

fr.2017.6.063

\begin{abstract}
Puto seko and panganan are two Filipino rice and wheat flour-based delicacies. Modified recipes were used as treatments in making these products using $50 \%, 75 \%$ and $100 \%$ arrowroot starch (AS). The control used was made from 100\% all-purpose flour (APF) for puto seko and $100 \%$ rice flour (RF) for panganan. Twenty-five panelists were used for the sensory attributes assessment of the products using a 5-point hedonic scale for colour, aroma/flavour, texture or mouthfeel, taste and general acceptability. The most acceptable treatments were subjected to proximate analyses. The sensory evaluations of puto seko and panganan with $100 \%$ arrowroot starch have more acceptable attributes than the control at $(\mathrm{p}<0.05)$. Proximate analysis of puto seko with $100 \%$ arrowroot starch showed $6.16 \%$ moisture, $15.95 \%$ fat, $1.26 \%$ protein, $0.74 \%$ ash, $0.50 \%$ fiber and $75.39 \%$ carbohydrates; while the panganan made has $9.93 \%$ moisture, $9.53 \%$ fat, $2.35 \%$ protein, $0.63 \%$ ash, $0.67 \%$ fiber and $76.89 \%$ carbohydrates. Arrowroot starch can be used in making these two Filipino delicacies with better sensory attributes than the original products made from all-purpose flour and rice flour.
\end{abstract}

\section{Introduction}

Root and tuber crops are secondary sources of starch next to grains that provide high energy food in the form of carbohydrates per hectare per day as compared to other crops (Scott, 2000). They are low-cost energy foods since they require low inputs and can be grown in marginalized lands (Oke et al., 1990). Most of these crops are grown by subsistence farmers on small plots in the tropics (Oke et al., 1990; Collins, 1993; Hoover, 2001; Lebot, 2009), thus considered as important crops for food security among poorer countries (Scott et al., 2000a; Scott et al., 2000b).

Worldwide, the majority of research on root and tuber crops are primarily focused on cassava, potato, sweet potato, yams and aroids (Lebot, 2009). They are not given proper attention due to low commercial value (Wickramasinghe et al., 2009), poor storage and lack of general knowledge on their functional properties for value-adding research to the products (Aprianita et al., 2014).
Arrowroot (Maranta arundinacea) is one tropical root crop that has not been properly given attention for cultivation and product utilization. The plant is believed a native of West Indies and introduced worldwide during the colonization time (Raymond and Squires, 1959) and cultivated in the West Indies to produce starch for export to Canada, Europe, UK and USA (Erdman, 1986).

In the Philippines, especially in the island province of Marinduque, arrowroot has been naturalized as perineal root crop as supported by the Department of Science and Technology (DOST) for the production of bakery products (Andam and Labay, 2010). The province is known for its arrowroot delicacies, such as cookies, polvoron (Spanish shortbread) and saludsod (arrowroot pancake with grated young coconut meat).

As part of product value-adding, this study looked at the acceptability and proximate composition of puto seko (Philippine butter cookies) and panganan (Deep-fried finger-sized fritters) using arrowroot starch (AS). The said delicacies are commonly sought by local and foreign 
tourists alike every time they visited the province of Marinduque. Originally, these two delicacies are rice and wheat flour-based products. Puto seko is a common Filipino delicacy characterized by its powdery, light cream appearance with sweet creamy aroma and taste, while panganan is made only in Marinduque and known for its finger sized fritters with golden brown appearance and sugary sweet flavour of jaggery. The inner portion of the fritter is sweet and finely textured to gritty.

Studies revealed that arrowroot rhizome is rich in starch (Spennemann, 1992) that can yield 85\% starch when properly processed (Raja and Sindhu, 2000; Aprianita et al., 2014). Senavirathna et al., (2014) reported that its boiled rhizome had $73.4 \%$ moisture, $1.8 \%$ fat, $8.6 \%$ protein, $4.0 \%$ ash, $64.0 \%$ carbohydrates, $11.0 \%$ insoluble dietary fiber and $6.0 \%$ soluble dietary fiber. Kumalasari et al. (2012) reported that its starch has $11.9 \%$ moisture, $0.58 \%$ ash, $0.14 \%$ protein, $0.84 \%$ fat, $8.7 \%$ insoluble dietary fiber and $5.0 \%$ soluble dietary fiber, while Aprianita et al. (2014) found it to have $10.2 \%$ moisture, $0.60 \%$ protein, $21.9 \%$ amylose and $62.3 \%$ amylopectin. Furthermore, the amylose content of the starch showed different reports, such as $22 \%$ (Kim et al., 1984), 19.0-19.9\% (Erdman, 1986), 15.21\% (Pérez and Lares, 2005) and 24.8\% (Madineni et al., 2012). But Pérez and Lares (2005), reported that it has high amylopectin content of $84.79 \%$. In contrast, the amylose and amylopectin content of wheat flour ranges from 25 $28 \%$ amylose and $72-75 \%$ amylopectin (Van Hung et al., 2006; Chen, et al., 2016).

Furthermore, it revealed that arrowroot starch has no gluten content (Shepherd and Gibson, 2006), high digestibility (Jyothi et al., 2009), high dietary fibers, raffinose, lactulose, stachyose (Harmayani et al., 2011) and high fructo-oligosaccharides (Fitri, 2011), which can be potential prebiotics (Kumalasari et al., 2012; Abesinghe et al., 2012). Thus, the study used arrowroot starch as additive and or substitute to the original rice flour (RF) and all-purpose flour (APF) in making puto seko and panganan.

\section{Materials and methods}

\subsection{Arrowroot starch (AS) extraction.}

Rhizomes were harvested from the field trials of the School of Agriculture of Marinduque State College at Torrijos Campus. The freshly harvested rhizomes were cleaned, washed and rasped for 10-15 minutes using the fabricated Arrowroot Rasping Machine developed by one of the faculties of the College. The machine has a mean capacity of $46.2 \mathrm{~kg} / \mathrm{hr}$ with starch recovery of $16.12 \%$ (Pascua, 2015). The rasped rhizomes were placed in a finely mesh abaca cloth and squeezed them by hand with enough water. The starch was collected in an aluminum basin and washed three times with potable water until the yellowish-brown supernatant liquid turned clear and the settled starch turned white. The starch was separated from the supernatant liquid, dried in a solar drier at a mean temperature of $45^{\circ} \mathrm{C}$ for six hours then shifted into powdery substance to remove the bigger lumps.

\subsection{Test delicacies preparation}

\subsubsection{Puto seko}

The dough was prepared from ratios of AS: $50 \%+$ APF: $50 \%$ as $\mathrm{T}_{1}, 75 \%: 25 \%$ as $\mathrm{T}_{2}$, AS: $100 \%$ as $\mathrm{T}_{3}$ and $100 \%$ APF as a control. Creamed butter, sugar, whipped eggs and baking powder were added and kneaded until soft and pliable. Each combination was pressed into a cookie mold, placed on a baking sheet and baked at an average temperature of $134.75^{\circ} \mathrm{C}$ for 20 minutes, then cooled for 15 minutes before packing in the microwaveable material.

\subsubsection{Panganan}

Arrowroot starch (AS) and rice flour (RF) combination was made at ratios of 50:50 as $\mathrm{T}_{1}, 75: 25$ as $\mathrm{T}_{2}, 100 \%$ AS as $\mathrm{T}_{3}$ and $100 \% \mathrm{RF}$ as a control. Each combination was mixed well, toasted with continuous stirring in a pan for 10 minutes at an average temperature of $60^{\circ} \mathrm{C}$ and then set aside to cool at $30^{\circ} \mathrm{C}$. A sugary slurry was made by dissolving a cup of grated sugarcane jaggery (locally known as matamis na bao or panutsa) in two cups of water, then heated at $80^{\circ} \mathrm{C}$ for five minutes with continuous stirring until totally dissolved. The toasted combinations of AS and RF and the 100\% AS and $100 \%$ RF have shifted again and combined each with jaggery slurry at a proportion of $1: 1.5$. They were mixed and kneaded well, then finally shaped into finger sized sticks with lengths of $7.0 \mathrm{~cm}$. These were rolled in rice flour (RF) and finally deep fried in coconut oil at an average temperature of $80^{\circ} \mathrm{C}$ for two minutes until golden brown. The excess oil was drained on paper towel and packed in sealable PP or PE bags.

\subsection{Sensory evaluation}

Twenty-five panelists composed of consumers, students and bakers were requested to evaluate the newly prepared delicacies. The panelists were selected based on familiarity with the two products. Ten minutes after baking, the samples were evaluated in terms of colour/ 
appearance, aroma/flavour, texture or mouthfeel, taste and overall acceptability using a 5-point Hedonic scale ranging from like extremely (5) to dislike extremely (1).

Three replicates for each treatment per delicacy were coded and presented randomly to the panelists at room temperature. Each panelist was served with a whole piece of the delicacy, one treatment at a time in random order. Bottled mineral water was provided to the evaluators for mouth rinse before another set of a sample of delicacy was given to them at one to two-minute interval. They were instructed to evaluate each sample in the order they were served to them to eliminate possible biases and requested to rate them at once using a score card with 5-point Hedonic scale.

\subsection{Proximate composition}

Proximate analyses of the most acceptable products of puto seko and panganan with arrowroot starch were determined in terms of percent moisture, ash, crude fat, crude protein, fiber and free nitrogen extract, using the methods used by the Association of Official Analytical Chemists (AOAC, 2006).

\subsection{Statistical analysis}

All values for the sensory evaluation scores of the prepared delicacies were presented as mean scores and subjected to analysis of variance at $(p<0.05)$ level of significance. All mean scores for colour/appearance, aroma/flavour, texture or mouthfeel, taste and general acceptability were interpreted using the following ranges with the following adjectival ratings:

$\begin{array}{ll}4.50-5.00 & \text { Like extremely } \\ 3.50-4.49 & \text { Like very much } \\ 2.50-3.49 & \text { Neither Like nor dislike } \\ 1.50-2.49 & \text { Dislike very much } \\ 0.50-1.49 & \text { Dislike extremely }\end{array}$

Significant differences between means were identified by Duncan's multiple range tests at $(p<0.05)$. All values for the proximate composition of the most acceptable products were reported as means of three replicates.

\section{Results and discussion}

\subsection{Sensory evaluation of puto seko}

The sensory attributes of puto seko with arrowroot starch (AS) and all-purpose flour (APF) are presented in Table 1. The colour of the product affects the preferences of the panelists, thus, there was a significant difference in the colour/appearance of the puto seko made at $(p<0.05)$. The off-white appearance of the product with $100 \%$ AS was preferred by the panelists with a mean rating of 4.60 and given with adjectival rating of "like extremely". It was observed that an increase in the amount of APF generally made the product light brown to speckled brown in colour. This browning of baked products could be attributed to Maillard reaction, due to the chemical reaction between the present amino acids and reducing sugar in the starch, flour and added ingredients (Martins et al., 2000). The off-white colour of the product with $100 \%$ AS could be due to the low amino acid content of arrowroot starch (Kumalasari et al., 2012; Aprianita et al., 2014) as compared to APF.

The light brown colour of products made from treatment 2, with $75 \%$ AS and the control, with $100 \%$ APF got mean ratings of 3.84 and 3.72 respectively. They were both adjectively rated "like very much" and thus have no significant difference at $(p<0.05)$. The speckled light brown to brown colour of products with $50 \%$ AS got a mean rating of 3.16 , thus rated "neither like nor dislike" by the panelist.

A significant difference was observed in the products' aroma at $(p<0.05)$. The sweet sugary, pronounced aroma of butter in treatment 3, with $100 \%$ AS got the highest rating of 4.68, which means "like extremely". It was followed by the control (100\% APF) and treatment $2(75 \%$ AS) with mean ratings of 4.08 and 3.52 and thus "like very much" by the panelist. They noted that these products have also sweet sugary aroma, but with faint burnt smell. Treatment 1, with $50 \%$ AS, got a mean rating of 3.32, which means "neither like nor dislike". This product, according to the panelist has pronounced burnt sugar aroma. Furthermore, it was observed that increase in the amount of added APF to AS affects the aroma of the baked products. This could be attributed also to the Maillard reaction that occurred during the baking of the products, as this is related to the presence of free amino acids and reducing sugar (Martins et al., 2000) in the starch and added butter and eggs.

Differences in the texture or mouthfeel of the puto seco products were significantly observed by the panelist at $(\mathrm{p}<0.05)$. Treatment 3 , with $100 \%$ AS got the highest mean rating of 4.76 , thus rated "like extremely". The panelist noted the very fine texture of the product that generally "melt" in the mouth, thus not gritty and sticky as compared to the product available in the market. Treatment 2, with $75 \%$ AS and the control, with $100 \%$ APF got mean ratings of 3.84 and 3.60 respectively. A 
light gritty feel was observed in treatment 2 as noted by the panelist and a bit sticky for the control. But they were rated the same, "like very much" and thus not significantly different from each other at $(p<0.05)$. Treatment 1, with $50 \%$ AS was also not significantly different from the control, with a mean rating of 3.24 (neither like nor dislike). The panelist also observed a bit grittiness and stickiness in the products. This mouthfeel effect of the puto seco could be attributed to the amylose and amylopectin contents of the starch used. The higher the amount of amylopectin present the lower the hardness of the baked product and the higher the amylose content, the higher its hardness value (Horstmann et al., 2016). Studies revealed that arrowroot starch has low amylose and high amylopectin content (Erdman, 1986; Pérez and Lares, 2005) as compared to wheat flour with a high amount of amylose (Van Hung et al., 2006; Chen, et al., 2016).

There was a significant difference in the taste of the puto seko products made. The treatments with $100 \%$ AS, $75 \%$ AS and the control, with $100 \%$ APF have mean ratings of 4.44, 4.08 and 3.92 respectively, but showed no significant differences and they were rated as "like very much". The panelist noted the products as creamy and sweet all throughout. Only treatment 1, with $50 \%$ AS got an adjectival rating of "neither like nor dislike" or a mean rating of 3.04. The panelist noted the faintly burnt aftertaste of the product.

For the overall rating of the puto seko, significant differences among them were observed at $(p<0.05)$. The highest mean rating was obtained by treatment 3 , with $100 \%$ AS (4.56), thus "like extremely". This was followed by treatment 2, with $75 \%$ AS (3.76) and the control (3.56) which are both rated as "like very much". Treatment 1 , with $50 \%$ AS got a mean rating of 3.20 , which was interpreted as "neither like nor dislike". These findings further support the observations for the products' colour, aroma, texture or mouthfeel, and taste. The product with $100 \%$ AS was much favoured by the panelist and further addition of APF to AS affected the colour, aroma, mouthfeel, and taste of the puto seko.

\subsection{Sensory evaluation of panganan}

The sensory attributes of panganan are presented in Table 2. All the mean scores for the sensory attributes were rated "like extremely" to "like very much".

The golden brown colour of treatment 3, with $100 \%$ AS got a mean rating of 4.62 , thus rated by the panelist as "like extremely". This was followed by treatment 2 , the control and treatment 1 , with mean ratings of 4.41 ,
4.37 and 4.24 respectively, thus rated "like very much". Statistically, there were no significant differences observed at $(p<0.05)$ in the products' colour. This could be attributed to the deep frying of the products in coconut oil that gave a uniform golden brown colour to the finished products. The golden brown colour of the deep fried panganan could be attributed to Maillard reaction that did not change, despite the changes in the combination of rice flour (RF) and arrowroot starch (AS).

In terms of aroma, treatments 3 and 2, with $100 \%$ and $75 \%$ AS respectively, both got the highest mean ratings of 4.49 , which means "like very much". This was followed by the control, with a mean rating of 4.46 and treatment 1 , with $50 \% \mathrm{AS}$, with a mean rating of 4.24 . They were also rated as "like very much" and thus all the products have not shown significant differences at $(p<0.05)$ in terms of aroma. This could be attributed to the sugary sweet aroma of the jaggery that was further enhanced during frying. Thus, the addition of AS to RF did not affect the aroma of the products and the sugary sweet aroma of the jaggery predominates all throughout.

A significant difference was observed in the texture or mouthfeel of the panganan at $(\mathrm{p}<0.05)$. Treatments 3 and 2 got the highest mean ratings of 4.54 and 4.37 respectively, thus rated "like extremely" and "like very much". But statistically, these two products have no significant differences in terms of mouthfeel. According to the panelist, the crust and the inner portion of the panganan have soft and smooth feel to the palate that gradually melted on the tongue. Treatment 1 , with $50 \%$ AS and the control, with $100 \%$ RF got mean ratings of 4.19 and 4.08 respectively and both rated "like very much". The panelist noted the crust and the inner portion of the products were gritty to sticky. These could be attributed to the high amylopectin content of AS compared to that in RF that rendered the baked product soft and smooth to the tongue and palate.

In terms of panganan's taste, treatment 2, the control and treatment 3 got mean ratings of 4.66, 4.49 and 4.46, respectively, thus rated as "like extremely" and the last two as "like very much". These three products were not significantly different at $(\mathrm{p}<0.05)$ in terms of taste. Treatment 1, with $50 \%$ AS got the lowest mean rating of 4.11 , but also rated as "like very much" and therefore statistically not found different from treatments 3 and the control. The panelist noted that the sugary taste of the jaggery prevailed in the baked products and therefore changes in the taste due to the addition of AS in RF was not observed by the panelist. 
Table 1. Sensory mean scores of puto seko made from arrowroot and all-purpose flour blends.

\begin{tabular}{|c|c|c|c|c|c|}
\hline Treatment & $\begin{array}{c}\text { Colour / } \\
\text { appearance }\end{array}$ & $\begin{array}{l}\text { Aroma / } \\
\text { flavour }\end{array}$ & $\begin{array}{l}\text { Texture or } \\
\text { mouthfeel }\end{array}$ & Taste & $\begin{array}{c}\text { Overall } \\
\text { acceptability }\end{array}$ \\
\hline $\mathrm{T}_{1}(\mathrm{AS}: 50 \%+\mathrm{APF}: 50 \%)$ & $3.16^{\mathrm{c}}$ & $3.32^{\mathrm{c}}$ & $3.24^{c}$ & $3.04^{\mathrm{b}}$ & $3.20^{c}$ \\
\hline $\mathrm{T}_{2}(\mathrm{AS}: 75 \%+\mathrm{APF}: 25 \%)$ & $3.84^{\mathrm{b}}$ & $3.52^{\mathrm{b}}$ & $3.84^{\mathrm{b}}$ & $3.92^{\mathrm{a}}$ & $3.76^{\mathrm{b}}$ \\
\hline $\mathrm{T}_{3}(\mathrm{AS}: 100 \%)$ & $4.60^{\mathrm{a}}$ & $4.68^{\mathrm{a}}$ & $4.76^{\mathrm{a}}$ & $4.44^{\mathrm{a}}$ & $4.56^{\mathrm{a}}$ \\
\hline Control (APF: 100\%) & $3.72^{\mathrm{b}}$ & $4.08^{\mathrm{b}}$ & $3.60^{\mathrm{bc}}$ & $4.08^{\mathrm{a}}$ & $3.56^{\mathrm{bc}}$ \\
\hline
\end{tabular}

Note:

1. $\mathrm{N}=25$ evaluators

2. AS (arrowroot starch), APF (all-purpose flour)

3. Mean values are three replicates of the test samples and those with different superscript letters are significantly different $(\mathrm{p}<0.05)$

4. Score range: $4.50-5.00$ (like extremely), $3.50-4.49$ (like very much), $2.50-3.49$ (neither like nor dislike), $1.50-$ 2.49 (dislike very much) and $0.50-1.49$ (dislike extremely)

Table 2. Sensory mean scores of panganan made from arrowroot and rice flour blends.

\begin{tabular}{lccccc}
\hline \multicolumn{1}{c}{ Treatment } & $\begin{array}{c}\text { Colour } / \\
\text { appearance }\end{array}$ & $\begin{array}{c}\text { Aroma } / \\
\text { flavour }\end{array}$ & $\begin{array}{c}\text { Texture or } \\
\text { mouthfeel }\end{array}$ & Taste & $\begin{array}{c}\text { Overall } \\
\text { acceptability }\end{array}$ \\
\hline $\mathrm{T}_{1}($ AS: $50 \%+$ RF: $50 \%)$ & $4.24^{\mathrm{ns}}$ & $4.24^{\mathrm{ns}}$ & $4.08^{\mathrm{b}}$ & $4.11^{\mathrm{b}}$ & $4.12^{\mathrm{b}}$ \\
$\mathrm{T}_{2}($ AS: $75 \%+$ RF: $25 \%)$ & $4.41^{\mathrm{ns}}$ & $4.49^{\mathrm{ns}}$ & $4.37^{\mathrm{a}}$ & $4.66^{\mathrm{a}}$ & $4.47^{\mathrm{a}}$ \\
$\mathrm{T}_{3}($ AS: $100 \%)$ & $4.62^{\mathrm{ns}}$ & $4.49^{\mathrm{ns}}$ & $4.54^{\mathrm{a}}$ & $4.46^{\mathrm{ab}}$ & $4.49^{\mathrm{a}}$ \\
Control (RF: $100 \%)$ & $4.37^{\mathrm{ns}}$ & $4.46^{\mathrm{ns}}$ & $4.19^{\mathrm{b}}$ & $4.49^{\mathrm{ab}}$ & $4.19^{\mathrm{b}}$ \\
\hline
\end{tabular}

Note:

1. $\mathrm{N}=25$ evaluators

2. AS (arrowroot starch), RF (rice flour)

3. Mean values are three replicates of the test samples and those with different superscript letters are significantly different, ns means "not significant" $(\mathrm{p}<0.05)$

4. Score range: $4.50-5.00$ (like extremely), $3.50-4.49$ (like very much), $2.50-3.49$ (neither like nor dislike), $1.50-$ 2.49 (dislike very much) and $0.50-1.49$ (dislike extremely)
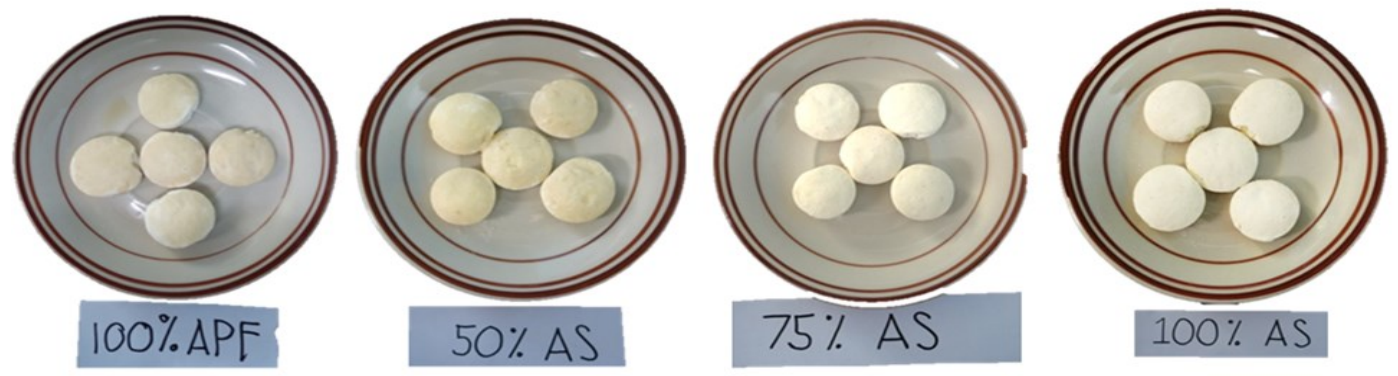

Figure 1. Samples of puto seko prepared with different amounts of arrowroot starch and all-purpose flour.
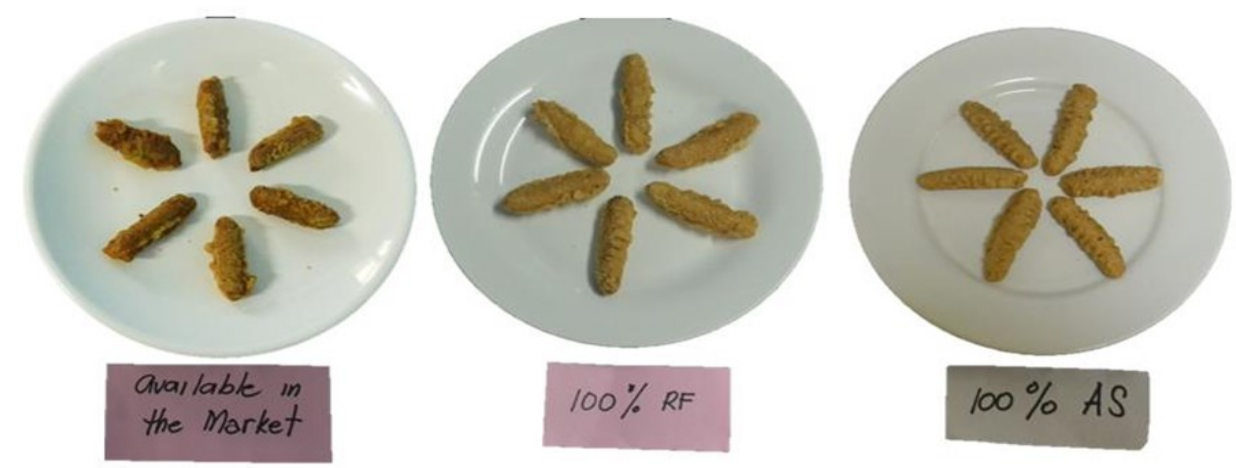

Figure 2. Samples of made panganan with arrowroot starch and rice flour. 
Significant differences were observed on the overall ratings of the panganan products. Treatments 3 and 2 got mean ratings of 4.49 and 4.47 respectively, while the control and treatment 1 , got mean ratings of 4.19 and 4.12 respectively. They were all rated "like very much". These results favour the products made from panganan with $100 \%$ and $75 \%$ AS that could be attributed more on the soft, smooth and easily melted AS to the tongue and palate of the panelists.

\subsection{Proximate analysis}

In addition to the acceptable sensory attributes of puto seko and panganan, their nutritional and energy values are also that important to guide the consumers and therefore should be an important component of the food's label for commercialization purposes. Thus, Table 3 presents the proximate composition of the studied baked products with $100 \%$ arrowroot starch.

Table 3. Proximate composition of the most acceptable products with $100 \%$ arrowroot starch.

\begin{tabular}{lcc}
\hline \multicolumn{1}{c}{$\begin{array}{c}\text { Proximate } \\
\text { composition (\%) }\end{array}$} & Puto seko & Panganan \\
\hline Moisture & $6.16 \pm 0.29$ & $9.93 \pm 0.28$ \\
Crude Fat & $15.95 \pm 0.46$ & $9.53 \pm 0.29$ \\
Crude Protein & $1.26 \pm 0.54$ & $2.35 \pm 0.67$ \\
Ash & $0.74 \pm 0.07$ & $0.63 \pm 0.04$ \\
Crude Fiber & $0.50 \pm 0.19$ & $0.67 \pm 0.75$ \\
Nitrogen Free & & 76.89 \\
$\begin{array}{l}\text { Extract } \\
\text { (Carbohydrates) }\end{array}$ & 75.39 & \\
\hline
\end{tabular}

Note: Values are means of three replicates

Panganan has a higher moisture content that puto seko because the latter was baked at a mean temperature of $134.75^{\circ} \mathrm{C}$ in order to attain its dry and crumbly appearance and texture. Puto seko can be stored longer than panganan, aside from the fact that the latter can become rancid if not properly processed and sealed in PP or PE pack.

Puto seko has higher fat content than panganan, which could be attributed from the creamed butter added, while the amount of fat in panganan could be attributed from the coconut oil used during deep frying of the products. The fat contents of the developed puto seko and panganan were found higher than the crude fat content of biscuits made from $100 \%$ cassava with $0.64 \%$ fat (Akobundu, 2009), 15\% sorghum and 85\% wheat flour biscuit that has 3.29\% fat (Adebowale et al. 2012) and $40 \%$ sweet potato and $60 \%$ wheat flour biscuit that has $5.53 \%$ fat (Singh et al., 2013).
In comparison with the proximate analysis of plainly boiled arrowroot rhizome, based on the findings of Senavirathna et al. (2014), the former has lower fat $(1.8 \%)$ and carbohydrate $(64.0 \%)$ contents, but has higher protein $(8.6 \%)$, ash $(4.0 \%)$ and fiber $(17.0 \%)$ contents than to seko and panganan, which can be attributed from varietal source and product ingredients used.

\section{Conclusion}

Arrowroot is one of the plants supported by the local government of Marinduque with financial and technical supports from the Department of Agriculture-Bureau of Agricultural Research (DA-BAR), the Department of Science and Technology (DOST) and Marinduque State College, preferably the School of Agriculture and the School of Technology. The province is known for its arrowroot cookies and part of continuous product development made by Marinduque State College, puto seko and panganan, two known Filipino delicacies were made from arrowroot starch.

Based on the results of this study, it has been found out that the best puto seko and panganan can be made by using $100 \%$ arrowroot starch, which was rated "like extremely" to "like very much" by the panelist. The products' sensory attributes were found better than the original products made from all-purpose flour and rice flour that are already available in the market. The addition of $75 \%$ arrowroot starch to all-purpose flour and rice flour in making puto seco and panganan gave almost similar results, thus the majority of the sensory attributes were rated as "like very much". As such, this study further revealed that arrowroot starch can be used to enhanced the acceptability level of puto seko and panganan in the market, which in the long run can help improve the income of the arrowroot farmers and processors of baked products in the province.

\section{Acknowledgement}

We would like to thank the Department of Agriculture - Bureau of Agricultural Research for the initial fund given to this research work. We also like to acknowledge the support of the Department of Science and Technology-MIMAROPA Region and the Norwegian Mission International at Buenavista, Marinduque. Special gratitude is extended to Dr. Alexander M. Pascua, Dean of the School of Agriculture at Torrijos Campus, Mrs. Nenita O. Gonzales, Food Technology Instructor of the School of Technology and 
Mrs. Marlyn A. Mayores, Assistant Professor of the School of Agriculture for sharing their knowledge and skills in completing this research work.

\section{References}

Abesinghe, N., Vidanarachchi, J. and Silva, S. (2012). The effect of arrowroot (Maranta arundinacea) extract on the survival of probiotic bacteria in set yoghurt. International Journals of Scientific Research Publications, 2(5), 14.

Adebowale, A.A., Adegoke, M.T., Sanni, S.A., Adegunwa, M.O., and Fetuga, G.O. (2012). Functional properties and biscuit making potentials of sorghum-wheat flour composite. American Journal of Food Technology, 7(6), 372-379.

Akobundu. (2009). Quality characteristics of cookies from composite flours of watermelon seed, cassava and wheat. Pakistan Journal of Nutrition, 8(7), 1097 -1102 .

Andam, C.J. and Labay, P.M. (2010). Arrowroot farming and processing in Marinduque. Department of Science and Technology-Region IV-B.

Aprianita, A., Vasiljevic, T., Bannikova, A., and Kasapis, S. (2014). Physicochemical properties of flours and starches derived from traditional Indonesian tubers and roots. Journal of Food Science and Technology, 51(12), 3669-3679.

Association of Official Analytical Chemists (AOAC). (2006). Official methods of analysis. $18^{\text {th }}$ ed. Gaithersburg, M.D.: AOAC

Chen, G.X., Zhou, J.W., Liu, Y.L., Lu, X.B., Han, C.X., Zhang, W.Y., Xu, Y.H. and Yan, Y.M. (2016). Biosynthesis and regulation of wheat amylose and amylopectin from proteomic and phosphoproteomic characterization of granule-binding proteins. Scientific Reports, 6, 33111.

Collins, W.W. (1993). Root vegetables: New uses for old crops. In Janick, J.and Simon, J.E. Simon (Eds.). New crops. New York: Wiley.

Erdman, M.D. (1986). Starch from arrowroot (Maranta arundinacea L.) grown at Tifton, Georgia. Cereal Chemistry, 63, 277-279.

Fitri, E.D.S. (2011). Effect of arrowroot cookies (Maranta arundinaceae L.) consumption on fecal bacteria profiles and chemical properties in under five years children. Indonesia: Universitas Gadjah Mada-Yogyakarta, MSc Thesis.

Harmayani, E., Kumalasari, I.D. and Marsono, Y. (2011). Effect of arrowroot (Maranta arundinacea
L.) diet on the selected bacterial population and chemical properties of caecal digesta of Sprague Dawley rats. International Research Journal of Microbiology, 2(8), 278-284.

Hoover, R. (2001). Composition, molecular structure and physicochemical properties of tuber and root starches: A review. Carbohydrate Polymers, 45(3), 253-267.

Horstmann, S.W., Belz, M.C., Heitmann, M., Zannini, E. and Arendt, E.K. (2016). Fundamental study on the impact of gluten-free starches on the quality of gluten-free model breads. Foods, 5(2), 30.

Jyothi, A.N., Sheriff, J.T. and Sajeev, M.S. (2009). Physical and functional properties of arrowroot starch extrudates. Journal of Food Science, 74(2), E97-E104.

Kim, K., Yoon, H.K. and Kim, S.K. (1984). Physicochemical properties of arrowroot starch. Journal of the Korean Chemical Society, 27, 245251.

Kumalasari, I.D., Harmayani, E., Lestari, L.A., Raharjo, S., Asmara, W., Nishi, K. and Sugahara, T. (2012). Evaluation of immunostimulatory effect of the arrowroot (Maranta arundinacea L.) in vitro and in vivo. Cytotechnology, 64(2), 131-137.

Lebot, V. (2009). Tropical root and tuber crops: cassava, sweet potato, yam and aroids. In Atherton, J. (Ed.) Crop production science in horticulture series. Wallingford: CAB International.

Madineni, M.N., Faiza, S., Surekha, R.S., Ravi, R. and Guha, M. (2012). Morphological, structural, and functional properties of maranta (Maranta arundinacea L) starch. Food Science and Biotechnology, 21(3), 747-752.

Martins, S.I., Jongen, W.M., and Van Boekel, M.A. (2000). Trends in Food Science and Technology, 11 (9), 364-373.

Oke, O.L., Redhead, J. and Hussain, M.A. (1990). Roots, tubers, plantains and bananas in human nutrition. Rome: FAO.

Pascua, A.M. (2015). Development and testing of an arrowroot (Maranta arundinacea) processing machine. School of Agriculture-Marinduque State College.

Pérez, E. and Lares, M. (2005). Chemical composition, mineral profile, and functional properties of Canna (Canna edulis) and Arrowroot (Maranta spp.) starches. Plant Foods for Human Nutrition (Formerly Qualitas Plantarum), 60(3), 113-116.

Raja, M.K.C. and Sindhu, P. (2000). Properties of steam- 
treated arrowroot (Maranta arundinacea) starch. Starch/Stärke, 52, 471-476.

Raymond, W.D. and Squires, J. (1959). Sources of starch in colonial territories II: Arrowroot (Maranta arundinacea Linn.). Tropical Science, 1, 182-192.

Scott, G.J. (2000). Roots and tubers in the global food system: A vision statement to the year 2020: Report to the Technical Advisory Committee (TAC) of the Consultative Group on International Agricultural Research (CGIAR). Iita.

Scott, G.J., Rosegrant, M.W. and Ringler, C. (2000a). Global projections for root and tuber crops to the year 2020. Food Policy, 25(5), 561-597.

Scott, G.J., Rosegrant, M.W. and Ringler, C. (2000b). Roots and tubers for the 21st century: Trends, projections, and policy options, Vol. 31. Peru: International Food Policy Research Institute.

Senavirathna, R.M.I.S.K., Ekanayake, S., Jansz, E.R. and Welihinda, J. (2014). Proximate composition, glycemic indices, and some factors affecting glycemic indices of underutilized tubers. StarchStärke, 66(11-12): 1041-1048.

Shepherd, S. and Gibson, P.R. (2006). Understanding the gluten-free diet for teaching in Australia. Nutrition and Dietetics 63, 155-165.

Singh, S., Riar, C S., and Saxena, D.C. (2013). Effect of incorporating sweet potato flour to wheat flour on the quality characteristics of cookies. African Journal of Food Science, 2(6), 065-072.

Spennemann, D.H. (1992). Arrowroot production in The Marshall Islands - Past, present and future. New Zealand Journal of Crop and Horticultural Science, 20(1), 97-97.

Van Hung, P., Maeda, T., and Morita, N. (2006). Waxy and high-amylose wheat starches and flourscharacteristics, functionality and application. Trends in Food Science and Technology, 17(8), 448-456.

Wickramasinghe, H.A.M., Takigawa, S., MatsuuraEndo, C., Yamauchi, H. and Noda, T. (2009). Comparative analysis of starch properties of different root and tuber crops of Sri Lanka. Food Chemistry, 112(1), 98-103 